\title{
Large stone in crossed unfused ectopic kidney with totally intrarenal pelvis
}

\author{
Jai Prakash, ${ }^{1}$ Vimala Swami, ${ }^{2}$ Bhupendra Pal Singh, ${ }^{1}$ Satyanarayan Sankhwar ${ }^{1}$
}

${ }^{1}$ Department of Urology, King George Medical University, Lucknow, Uttar Pradesh, India ${ }^{2}$ Department of Dental, King George Medical University, Lucknow, Uttar Pradesh, India

\section{Correspondence to}

Dr Jai Prakash,

drjpswami@gmail.com

Accepted 9 April 2014

\section{DESCRIPTION}

A 35-year-old man with no significant medical history presented with an 8-month history of dull pain in his right-lower abdomen. There was no relevant family history. Intravenous urography (IVU) was performed in a peripheral hospital (figure 1A-C) and showed a normal right kidney and an ectopic left kidney (at the L4-L5 level right to midline) with a $25 \mathrm{~mm}$ pelvic stone. We further performed CT urogram for complete anatomical details (figure 1D, E) and found a left-crossed renal ectopia (RE) with pelvic calculi and good contrast uptake and excretion by both kidneys, left ureter not excreted due to stone. Retrograde ureteropyelogram (figure 2A-C) delineated a normal calibre of the left ureter which crossed from the left to right side. In view of large stone burden, we opted for laparoscopic pyelolithotomy (figure 3A). Intraoperatively, there was a totally intrarenal pelvis and we found difficulty in progression (figure $3 \mathrm{~B}$ ), so the procedure was converted to open surgery and the stone was removed by extended pyelolithotomy (figure 3C).

$\mathrm{RE}$ is an unusual condition. ${ }^{1}$ Birmole et al mentioned that crossed RE was first described by Pannorlus in $1654 .^{2}$ It is a very uncommon condition and more than $90 \%$ are fused. ${ }^{3}$ Its coexistence with nephrolithiasis is even rarer. Nephrolithiasis in crossed unfused RE with totally intrarenal pelvis have not been reported to the best of our knowledge. CT urography is the gold standard for stones in normal as well as in anomalous renal excretory systems and IVU should not be performed.
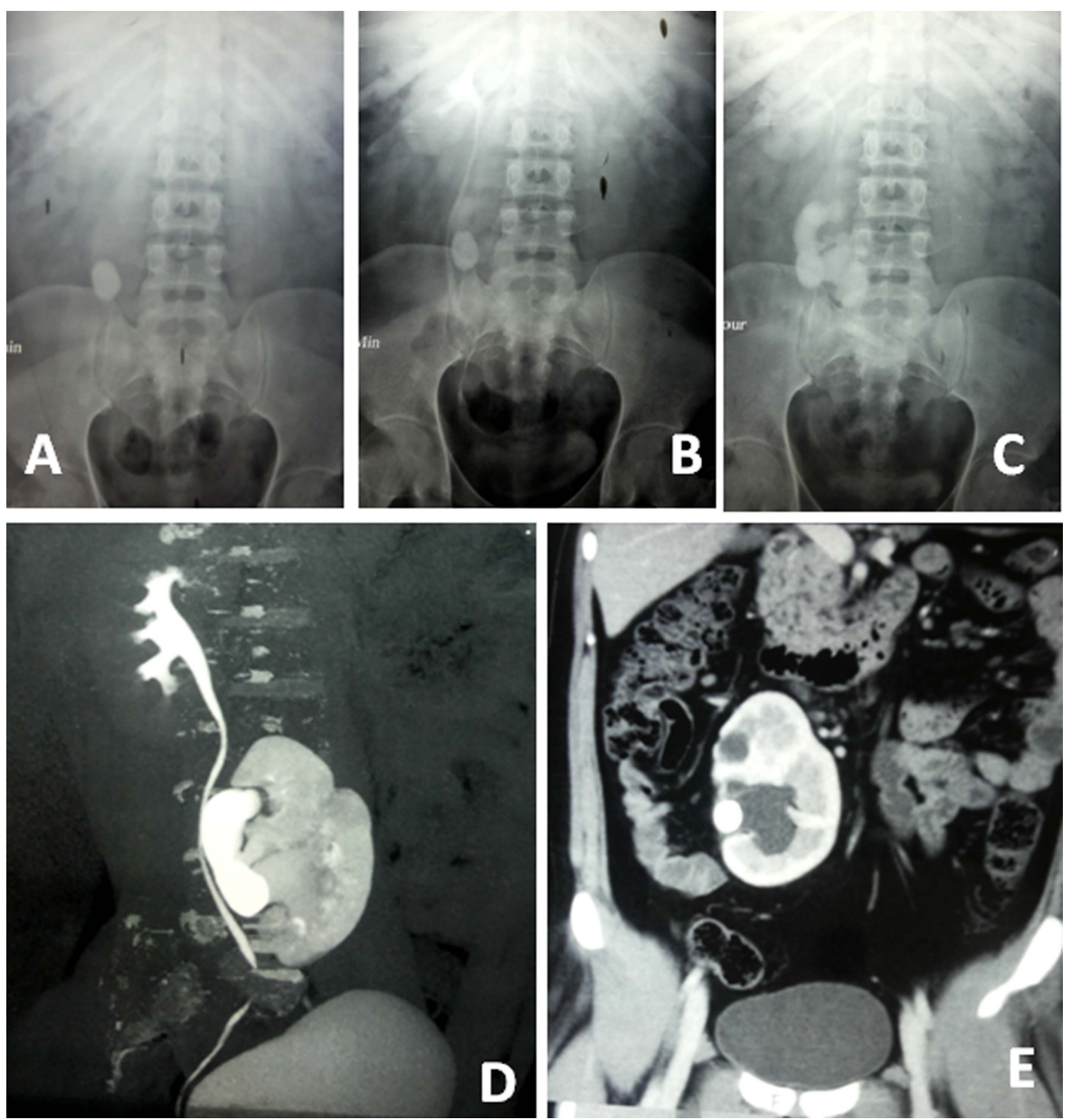

Figure 1 (A) X-ray of the kidneys, ureters, bladder showing radio-opaque shadow at the L4-L5 level, just above the right iliac crest. (B) Intravenous urography (IVU) at 15 min showing normal position of the right kidney and ectopic left kidney (at the L4-L5 level just medial to the right ureter). (C) IVU at $1 \mathrm{~h}$ delineating anatomy and function of both kidneys. (D) CT urogram demonstrating left crossed ectopia without fusion and good contrast uptake and excretion by both kidneys, left ureter not excreted due to stone. (E) Contrast CT showing stone in intrarenal pelvis of the ectopic kidney. 
Figure 2 (A) Fluoroscopic image taken before retrograde contrast study showing guide wire and stone in the left ectopic kidney. (B) Retrograde ureterography through left ureteric orifice showing crossing of ureter from the left to the right side. (C) Retrograde contrast study showing the pelvicalyceal system of the ectopic kidney.

Figure 3 (A) Laparoscopic picture showing left ectopic kidney with ureter (thin arrow) just medial-to-right ureter (thick arrow). (B) Laparoscopic picture showing entry of left ureter into the kidney (pelvis is not seen). (C) Picture showing opened pelvis with $\mathrm{JJ}$ stent in situ after open pyelolithotomy.
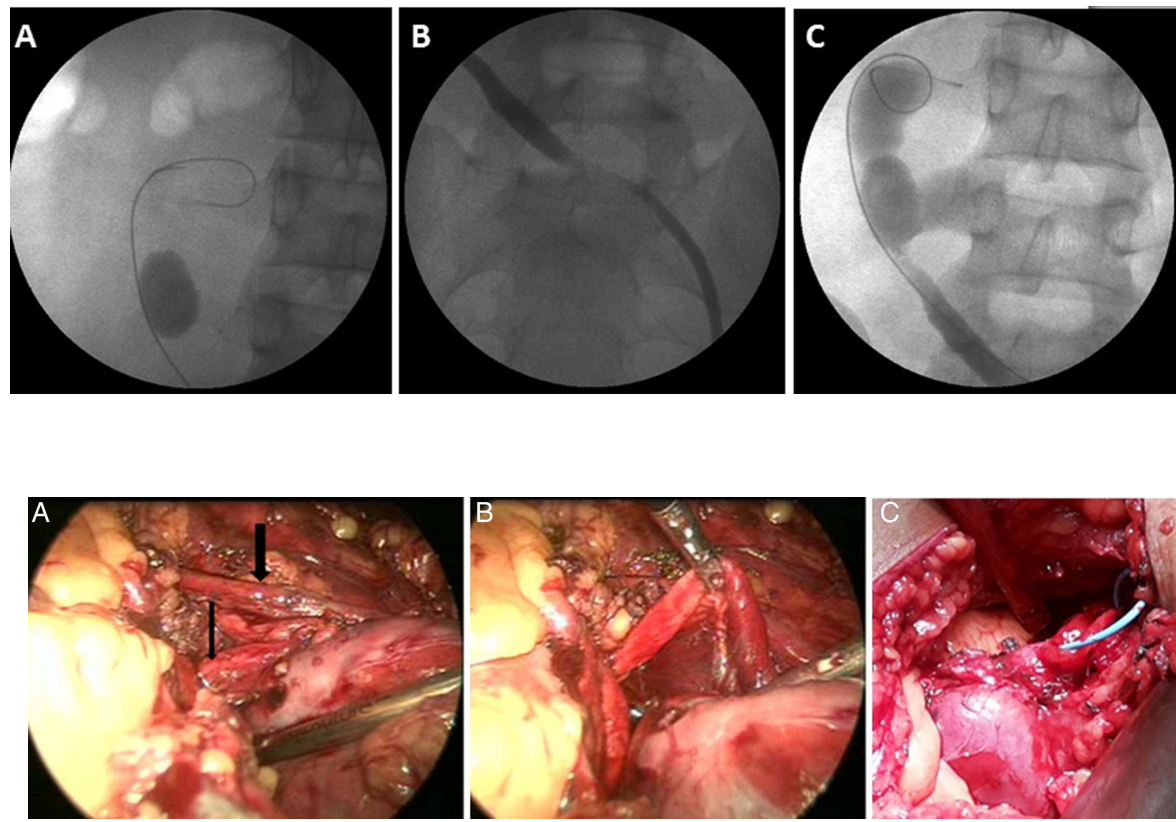

RE has an increased susceptibility for urinary tract infections and urolithiasis. ${ }^{4}$ Nephrolithiasis associated with RE could be treated by shock wave lithotripsy or various endourological and laparoscopic procedures depending on the size and location of stones. ${ }^{5-8}$ However, an anomalous location associated with a totally intrarenal pelvis poses a different surgical challenge and one should be ready for open conversion because laparoscopic approach may be difficult and non-progressive.

\section{Learning points}

- Renal ectopia is an unusual condition.

- Nephrolithiasis in ectopic kidney can be treated conservatively or with shock-wave lithotripsy, ureteroscopy, percutaneous nephrolithotomy, laparoscopic-guided percutaneous nephrolithotomy and laparoscopic pyelolithotomy depending on the size and location of stones.

- Renal ectopia with totally intrarenal pelvis poses a different surgical challenge and one should be ready for open conversion because laparoscopic approach may be difficult and non-progressive.

\section{Competing interests None.}

Patient consent Obtained.

Provenance and peer review Not commissioned; externally peer reviewed.

\section{REFERENCES}

1 Moore KL, Persaud TVN. Urogenital system. In: The developing human. Clinically oriented embryology. 8th edn. Philadelphia: WB Saunders, 2008:244-56.

2 Birmole BY, Brorwankar SS, Vaidya AS, et al. Crossed renal ectopia. J Postgrad Med 1993;39:149-51.

3 Dunnick NR, Sandler CM, Newhouse JH. Congenital anomalies. In: Textbook of uroradiology. 5th edn. Philadelphia; Lippincott Williams \& Wilkins, 2013:15.

4 Ahmad R. A rare association of crossed fused renal ectopia. BMC Nephrol 2007;8:5.

5 Chang TD, Dretller SP. Laparoscopic pyelolithotomy in an ectopic kidney. J Urol 1996:156:1753.

6 Zafar FS, Lingeman JE. Value of laparoscopy in management of calculi complicating renal malformations. J Endourol 1996;10:379-83.

7 Eshghi AM, Roth JS, Smith AD. Percutaneous transperitoneal approach to a pelvic kidney for endourologic removal of staghorn calculus. I Urol 1985:134:525-7.

8 Toth C, Holman E, Pasztor I, et al. Laparoscopically controlled and assisted percutaneous transperitoneal nephrolithotomy in a pelvic dystopic kidney. J Endourol 1993; 7:303-501.

Copyright 2014 BMJ Publishing Group. All rights reserved. For permission to reuse any of this content visit http://group.bmj.com/group/rights-licensing/permissions.

BMJ Case Report Fellows may re-use this article for personal use and teaching without any further permission.

Become a Fellow of BMJ Case Reports today and you can:

- Submit as many cases as you like

- Enjoy fast sympathetic peer review and rapid publication of accepted articles

- Access all the published articles

- Re-use any of the published material for personal use and teaching without further permission

For information on Institutional Fellowships contact consortiasales@bmjgroup.com

Visit casereports.bmj.com for more articles like this and to become a Fellow 